\title{
Epithelial cell proliferation in diverse models of experimental cholelithiasis
}

\author{
A. J. SCOTT
}

From the Department of Medicine, Auckland Hospital, Auckland, New Zealand

SUMMARY Proliferation of the epithelial cells of the gall bladder during the initial stages of experimental cholelithiasis has been studied by autoradiography. Rabbits taking a diet with $1 \%$ dihydrocholesterol added showed a rise in labelling index from $1.5 \%-19 \%$ by three days. Mice taking a $1 \%$ cholesterol $0.5 \%$ cholic acid diet showed a similar rise from less than $1 \%$ to $15-21 \%$ at two and five days. Guinea-pigs receiving lincomycin showed a rise from less than $1 \%$ to $6 \%$ after 24 hours. These changes, which appear well before the appearance of gall stones, together with previous reports of enhanced mucous secretion during lithogenesis, make it clear that in these laboratory models of cholelithiasis the gall bladder is abnormal well before stones form.

This paper is designed to help answer the question: is the gall bladder abnormal when gall stones are forming?

The ways in which the gall bladder will respond to injury have not been much studied. It seems likely, however, that the responses will be those common to mucous membranes elsewhere in the body and that the earliest reactions will be a proliferation of epithelial cells and increased mucous secretion (Florey, 1970). The normal gall bladder shows a slow rate of cell renewal (Scott, 1974), but that a dramatic acceleration of this rate is possible is shown by the reaction of the guinea-pig gall bladder after ligation of the common bowel duct (Scott, 1974), and the reaction of the cat gall bladder epithelium after surgical trauma (McMinn and Johnson, 1957). The explosion of mitotic activity which is seen in these situations contrasts sharply with the normal state and suggests that DNA synthesis by the gall bladder mucosa might act as a sensitive indicator of injury there.

Consequently the pattern of cell proliferation has been surveyed using autoradiographic methods in three laboratory animal models of cholelithiasis during the first days of gall stone induction and before stones have formed. The models chosen were the dihydrocholesterol fed rabbit (Freston et al., 1969), the cholesterol and cholic acid fed mouse (Caldwell et al., 1965) and the lincomycin treated guinea-pig (Scott, 1976).

\section{Methods}

DIHYDROCHOLESTEROL FED RABBITS

New Zealand white rabbits weighing $2 \cdot 2-2 \cdot 6 \mathrm{~kg}$ were used. There were four experimental animals and four control animals. The experimental animals received SG1 pellets which had been soaked in a solution of dihydrocholesterol in diethyl ether. The ether was then evaporated leaving the pellets containing $1 \%$ dihydrocholesterol. The experimental diet was less palatable than the unadulterated pellet. To allow for this, all animals were fed $100 \mathrm{~g}$ of pellets daily, which was a little less than the experimental animals were found to eat ad libitum. The weight of the animals in no case varied by more than $4 \%$ during the experiment.

After three days of feeding $0 \cdot 1 \mathrm{uCi} / \mathrm{g}$ body weight tritiated thymidine was injected into an ear vein. Six hours later the animals were killed by air embolism and the gall bladders removed.

Other rabbits were continued on the experimental diet to observe that stones did indeed form in the gall bladder on the experimental regime.

CHOLESTEROL-CHOLIC ACID FED MICE

Male SPF albino mice weighing 22-30 g were fed on a diet of ground pellets (diet 86) to which had been added $1 \%$ cholesterol and $0.5 \%$ cholic acid. Control animals were fed the ground pellet diet ad libitum. Three experimental mice were killed after two days and another three after five days. Three control animals were studied. On the day it was killed each mouse received $0.1 \mathrm{uCi} / \mathrm{g}$ body weight tritiated thymidine by intraperitoneal injection. It was then killed six hours later and the gall bladder removed.

Other mice were continued on the experimental diet and examined at intervals to observe that gall stones did indeed form. 


\section{LINCOMYCIN TREATED GUINEA-PIGS}

Guinea-pigs weighing 500-700 $\mathrm{g}$ and of either sex were fed a diet of pellets supplemented by hay and vitamin C. Four experimental animals received lincomycin (Lincocin, Upjohn) $60 \mathrm{mg} / \mathrm{kg}$ by subcutaneous injection. After 18 hours tritiated thymidine $0.1 \mathrm{uCi} / \mathrm{g}$ body weight was injected into the peritoneum. After a further six hours each animal was killed and the gall bladder removed. Four control animals were studied in the same way after pair feeding for 24 hours.

The effectiveness of this regime in inducing gall stones when continued for seven days and when the animal is allowed to survive to six weeks and beyond has previously been documented from this laboratory (Scott, 1976).

\section{AUTORADIOGRAPHIC TECHNIQUE}

Gall bladders were fixed in formalin, then mounted within paraffin blocks in such a way that fundus, body, and duct of the gall bladder could be identified in sections. These were cut $5 \mu$ thick. Autoradiographs were made by dipping slides in Kodak NBT-2 emulsion and allowing exposures of six to eight weeks before development. Haematoxylin and eosin ( $\mathrm{H}$ and E) and periodic acid Schiff (PAS) stains were used, the former being applied after development and fixation of the autoradiograph, the latter in two stages, the steps before acid hydrolysis preceding exposure and the final steps following fixation.

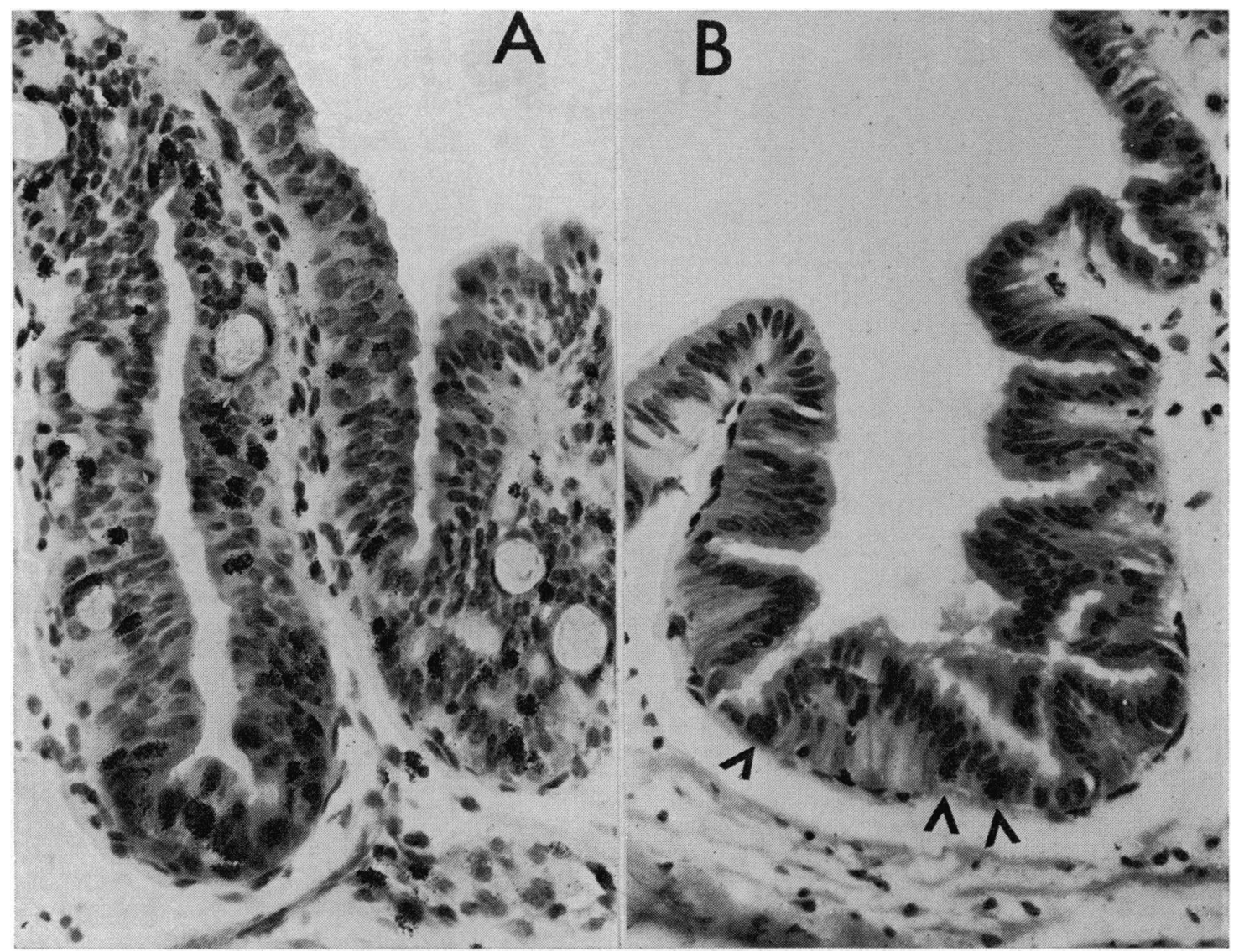

Fig. 1 Autoradiographs of rabbit gall bladder epithelium. A. For three days the rabbit had had SG1 pellets with $1 \%$ dihydrocholesterol. Tritiated thymidine was given six hours before death. Many epithelial cells are labelled, with labelling most marked at the valleys between nucosal folds. Glycoprotein filled interepithelial vesicles are prominent. $B$. Control rabbit showing sparsely labelled nuclei (arrowed) with a predilection for cells within the mucosal valleys. No vesicles are present and the epithelial cells form a regular pallisade. $H$ and $E \times 450$ (original magnification). 
Results

DIHYDROCHOLESTEROL TREATED RABBITS Three of the treated animals showed a marked increase in labelled nuclei, a disturbance of the normal pallisade pattern of the epithelial cells, and many large interepithelial vesicles. The fourth treated animal showed a more modest increase in labelled nuclei and sparse vesicles. The labelling index (labelled epithelial nuclei $\times 100$ divided by all epithelial nuclei) in the experimental animals averaged $19 \%$ compared with $1.5 \%$ in the controls. Labelled cells were found in all sites over the hills and valleys of the mucosal folds but labelling was particularly dense in the valleys. A comparison between experimental and control animals is illustrated in Fig. 1.
One of the four treated animals was found to have small stones present in the gall bladder bile, but stones were not present in others in which, nevertheless, similar histological changes were found. Cell proliferation therefore appeared to be independent of stone formation.

CHOLESTEROL-CHOLIC ACID TREATED MICE Control mice showed sparse nuclear labelling. Experimental mice examined after either two or five days showed dramatic changes. The regular pattern of low columnar epithelial cells seen in control mice was changed for one in which pencil cells and casket cells were frequent, and the nucleus in many cells was apical rather than basal. The labelling index, less than $1 \%$ in controls, was $15-21 \%$ in the various treated animals. Labelled nuclei were found in all sites with-

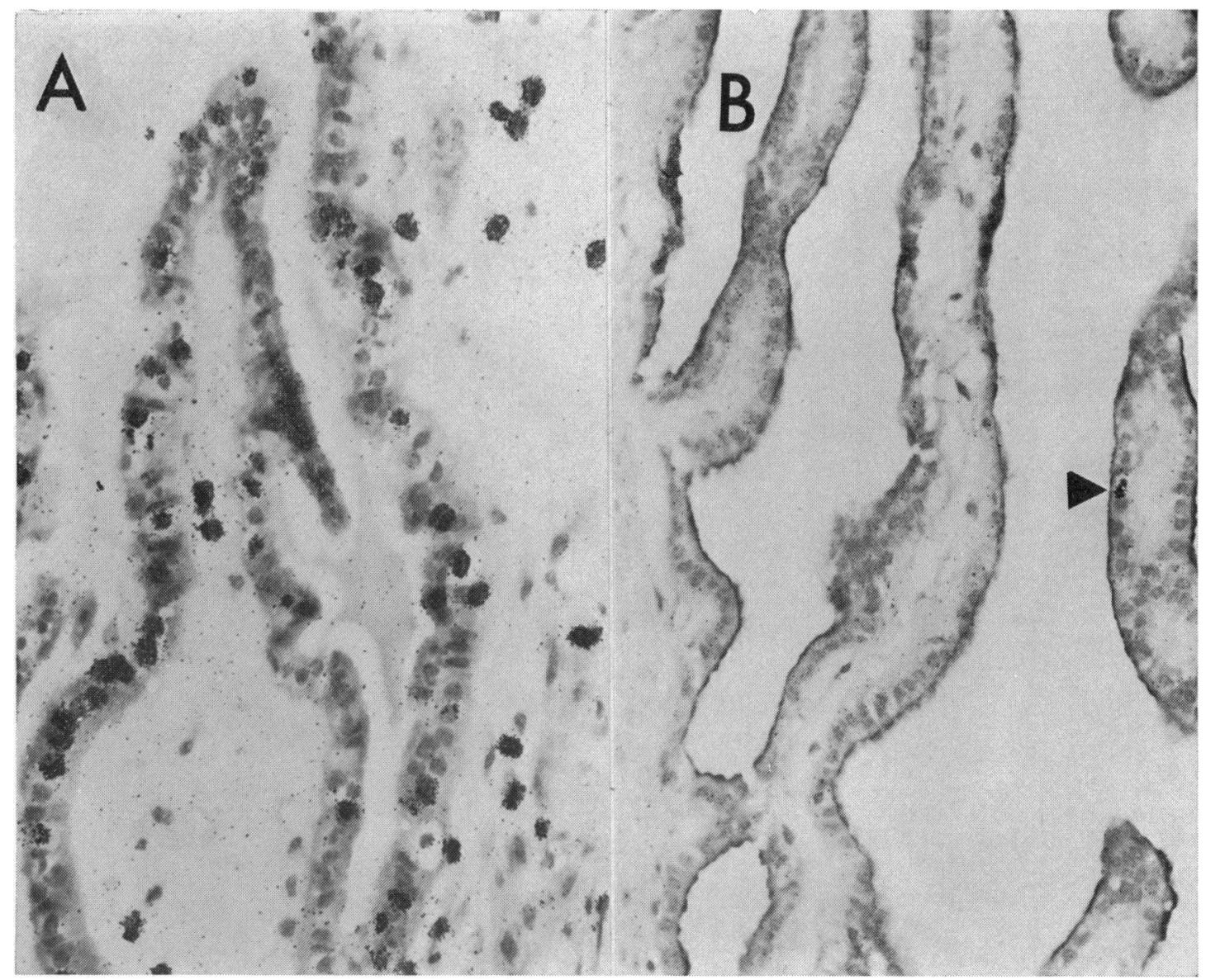

Fig. 2 Autoradiographs of mouse gall bladder. A. For two days the mouse had been fed diet 86 with $1 \%$ cholesterol and $0.5 \%$ cholic acid. Many epithelial and connective tissue cell nuclei are labelled. The epithelial cells are pleomorphic and the lamina propria is oedematous. $H$ and $E \times 450$ (original magnification). B. Control mouse showing one labelled nucleus in the entire field (arrowed). Many similar fields failed to show a single labelled epithelial cell. $P A S \times 450$ (original magnification). 
out any predilection for the hills or valleys of the mucosal folds. The lamina propria showed oedema and there were many labelled fibroblasts there. Figure 2 compares a gall bladder of an animal treated for two days with a control.

At three and five days of treatment there were no gall stones. Indeed in other animals followed for up to eight weeks gall stones were never seen before four weeks, in keeping with other reports of cholesterol-cholic acid treated mice (Caldwell et al., 1965).

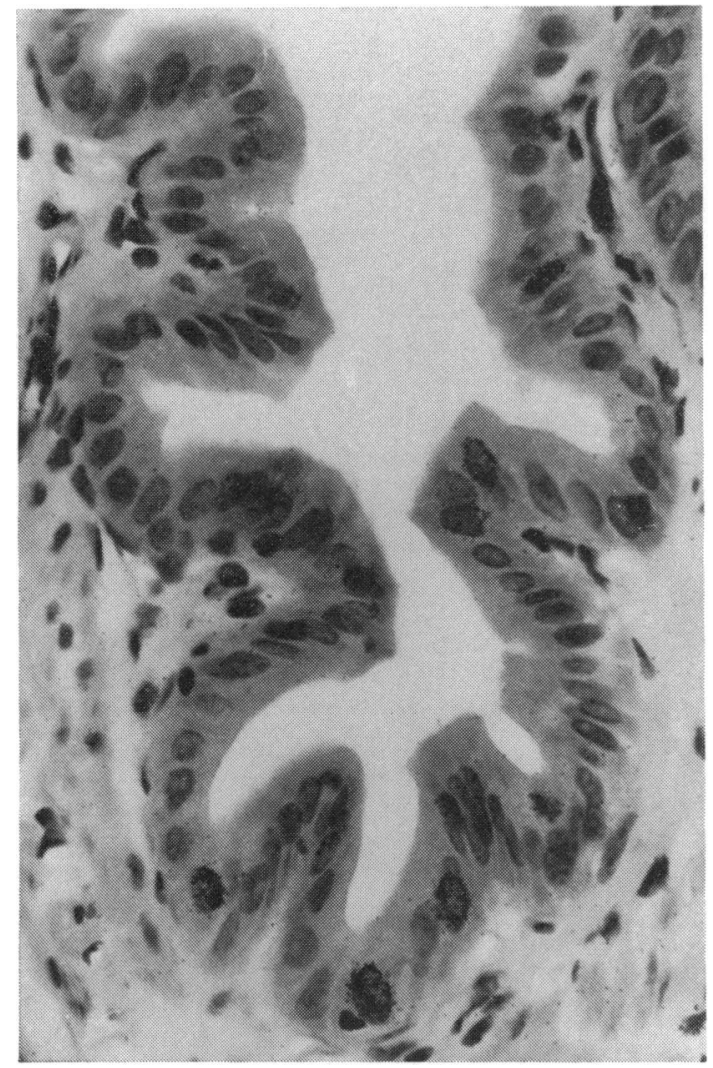

Fig. 3 Autoradiograph of guinea-pig gall bladder. Lincomycin was given $60 \mathrm{mg}$ per $\mathrm{kg}$ and after 18 hours tritiated thymidine was given intraperitoneally. Six hours later the animal was killed. Many labelled nuclei are present. Control animals showed no label in most similar fields. $H$ and $E \times 450$ (original magnification).

\section{LINCOMYCIN TREATED GUINEA-PIGS}

The pattern of cell proliferation in treated animals has been previously documented from this laboratory (Scott, 1976). The present study confirmed that after a single injection of lincomycin, and before the development of turbid bile, the labelling index rose from less than $1 \%$ to $6 \%$. No other histological change was found at 24 hours (Fig. 3).

\section{Discussion}

Gall stones of western man form in the gall bladder. Such a gall bladder, containing gall stones, often appears normal to the histologist (Boyd, 1965). That is to say, the histologist may not find evidence of inflammation such as congestion, oedema, and leucocytic infiltration. These mesenchymal reactions, however, are late in the sequence that occurs when a mucous membrane is damaged (Florey, 1970). Classical inflammatory reactions therefore provide a poor and insensitive indicator to use in judging whether the gall bladder is reacting to injury at the time gall stones are forming or have formed.

In other mucous membranes cell proliferation and mucous secretion are the earliest reactions to injury (Florey, 1970). That secretion of mucous is enhanced early in the course of lithogenesis has been shown for the rabbit (Freston et al., 1969) and the guinea-pig (Scott, 1976), of the models studied here, and this has also been shown in hamsters fed on a casein sucrose diet and forming cholesterol stones (Womack, 1971). That cell proliferation was likely to be enhanced in the dihydrocholesterol fed rabbit had been suggested by the appearance of interepithelial vesicles (Hayward et al., 1968), and cell proliferation had been shown to be present at one and two days in the lincomycin treated guinea-pig (Scott, 1976). This present study has shown that cell proliferation is indeed an early and striking response of the gall bladder to the introduction of the diet or drug that eventually leads to stone formation.

There is therefore good evidence in these three models of cholelithiasis that the gall bladder has been injured long before stones have formed there. While it is necessary to survey the physiological and biochemical consequences of this damage before it is possible to ascribe roles to the gall bladder mucosa in lithogenesis, it seems possible that cell proliferation is a prelude to metaplasia (Scott, 1976) and this would be expected to result in qualitative changes in gall bladder function. Is it possible that the latent period, between the initiation of the dietary or drug injury and the development of stones days or weeks later, is the period necessary for the gall bladder to mount a sufficient response to continuing injury to then become the trigger to the precipitation of stones?

Dr S. P. Lee, Dr Susan Hartley, and Miss Robyn Rastrick made important contributions to this study. Their help is gratefully acknowledged. This study was 
supported by the Medical Research Council of New Zealand.

References

Boyd, W. (1965). Pathology for the Physician, p. 501. Lea and Febiger: Philadelphia.

Caldwell, F. T., Jr., Levitsky, K., and Rosenberg, B. (1965). Dietary production and dissolution of cholesterol gallstones in the mouse. American Journal of Physiology, 209, 473-478.

Florey, H. W. (1970). The secretion of mucus and inflammation of mucous membranes. In General Pathology, pp. 195-225. Edited by H. W. Florey. Lloyd Luke: London.
Freston, J. W., Bouchier, I. A. D., and Newman, J. (1969). Biliary mucous substances in dihydrocholesterol-induced cholelithiasis. Gastroenterology, 57, 670-678.

Hayward, A. F., Freston, J. W., and Bouchier, I. A. D. (1968). Changes in the ultrastructure of gall bladder epithelium in rabbits with experimental gallstones. Gut, 9, 550-556.

McMinn, R. M. H., and Johnson, F. R. (1957). Wound healing in the gallbladder of the cat. British Journal of Surgery, 45, 76-80.

Scott, A. J. (1974). Are there proliferative compartments in the gallbladder? Gastroenterology, 67, 1231-1237.

Scott, A. J. (1976). Lincomycin-induced cholecystitis and gallstones in guinea pigs. Gastroenterology, 71, 814-820.

Womack, N. A. (1971). The development of gallstones. Surgery, Gynecology, and Obstetrics, 133, 937-945. 